\section{Blurred line on nicotine}

Sir, I agree with the author of the letter on nicotine pouches that we as dentists should update our knowledge regarding new products under the garb of being 'safe' when the only word we have is that of the manufacturer. ${ }^{1}$ While they may be utilised for recreational purposes, nicotine pouches are sold as a means of nicotine replacement therapy in Norwegian pharmacies, approved by the Norwegian Medicines Agency for the purpose of smoking cessation under the brand name 'Zonnic.',3

The manufacturer recommends using not more than 8-12 pouches per day, never to exceed 24. A stated feature of these pouches is that the user can control the release rate by moving the pouch around the mouth for a faster release and leaving it in place for a slower effect. ${ }^{4}$

Another major difference between this product and other nicotine replacement therapies is the fact that this particular product is manufactured by a commercial tobacco company rather than a pharmaceutical. These products should be viewed with extreme caution as they threaten to blur the line between nicotine replacement therapy and smokeless tobacco.

V. Sahni, New Delhi, India

\section{References}

1. Keogh A. Nicotine pouches. Br Dent J 2021; 230: 61-62.

2. The Common Catalog. Zonnic. Available at: https:// www.felleskatalogen.no/medisin/pasienter/pil-zonnicniconovum-592238 (accessed 22 January 2021).

3. Health Norway. Quit snus and smoking. Available at: https://www.helsenorge.no/snus-og-roykeslutt/ (accessed 22 January 2021)

4. Zonnic. Zonnic pouches. Available at: https://www. zonnic.com/pouches/ (accessed 22 January 2021).

https://doi.org/10.1038/s41415-021-2855-9

\section{Aesthetic dentistry}

\section{Clip-on questions}

Sir, on wasted hours scrolling through Instagram and Facebook feeds, I have been bombarded with 'clip on veneers' (COV) adverts. One showed several pictures of a lady grinning, displaying a large whiteboard smile enhanced with a fancy filter but the 'pre-op' photo showed several clear ongoing dental issues including anterior caries, gingival inflammation, and broken-down teeth. It does not surprise me that people are drawn to these kinds of products; the rise of social media advertising has facilitated an endless drive for the 'perfect smile'.
The company website selling these prostheses shows multiple client cases, many with the aforementioned dental issues. Obviously, these clients want a quick fix which is affordable, and at only $£ 200$ for both the impression kit and veneers, you cannot blame them for purchasing these products. The company claims that their COV are not only an aesthetic treatment option but also an 'alternative' to dental implants, dentures and other fixed prostheses and add that there is no need for any dental visits or complex procedures. These claims are both worrying and damaging.

A previous letter to the $B D J$ highlighted the short-term risks of COV which can become fixed in situ and cause oral ulceration and further deterioration of the oral tissues. ${ }^{1}$ Furthermore, these veneers can delay patients seeking dental professional intervention, only compounding the issues further. I feel as our regulator, the GDC should be looking into these companies as there is a similarity between the cases brought forward against direct-to-consumer orthodontics. ${ }^{2}$

J. Eaton, Gloucester, UK

\section{References}

1. Jadun S, Monaghan L, Darcey J. DIY dentistry: Clip-on veneer. Br Dent J 2018: 224: 557.

2. General Dental Council. Providing dental care remotely. 24 February 2020. Available at: https://www.gdc-uk. org/news-blogs/news/detail/2020/02/24/providingdental-care-remotely (accessed 30 December 2020).

https://doi.org/10.1038/s41415-021-2856-8

\section{Canine trends in SE Asia}

Sir, there is a popular trend in the South East Asian region that involves patients in need of orthodontic treatment preferring to align all the other teeth leaving high canines untouched, due to traditional beliefs. Despite explanation of the problems with carrying out such treatment, patients insist on keeping their high canines or avoiding orthodontics altogether. $^{1}$

There are also many patients desiring sharp pointy canines which is in stark contrast to what most published literature reports. A few years ago there was a trend in Japan where young teenage patients were visiting clinics asking for elongated canines or 'Yaeba'. This was principally for aesthetic reasons and dentists placed artificial resin-made canines on top of the natural canines with temporary cement. This procedure has gained massive popularity in the last decade and the trend has slowly but surely spread to SE Asia.
The Asian region is known for dental trends that rise every few years in part due to media frenzy. ${ }^{2}$ In the first decade of this century, a sudden surge of patients requested small diamonds to be bonded to their teeth, a popular procedure with female patients still in demand. Then came the era of fake braces which gained popularity among patients even after being denounced by orthodontists and dentists alike. Despite the efforts of dental and orthodontic associations, cases suffering from the ill-effects of such fake braces are still seen.

A prominent researcher in the field of communication studies reports that even though the aesthetic and beauty concepts keep changing, the factor responsible for their rise and fall is the fixation with youth.

A. Marya, A. Venugopal, Phnom Penh,

Cambodia

\section{References}

1. Theobald A H, Wong B K J, Quick A N, Thomson W M The impact of the popular media on cosmetic dentistry. NZDent J 2006: 102: 58-63.

2. Tortopidis D, Hatzikyriakos A, Kokoti M, Menexes G, Tsiggos N. Evaluation of the relationship between subjects' perception and professional assessment of esthetic treatment needs. J Esthet Restor Dent 2007; 19: 154-162.

https://doi.org/10.1038/s41415-021-2857-7

\section{Urgent dental care}

\section{Inpatient dental care}

Sir, in England, urgent dental care for inpatients is not described within the commissioning standard for urgent dental care and this means that regional commissioners will exclude inpatients when commissioning primary care services, such as Community Dental Services (CDS) who might have historically provided domiciliary care to hospitals without dental or maxillofacial units. This is in comparison to Scotland and Wales, where dental treatment for hospital inpatients is provided by the CDS. ${ }^{2,3}$

Reflecting on the impact of COVID-19 and the call to work more collaboratively with health partners within integrated care systems to improve overall health of the population, there should be discussion about local responsibilities to provide urgent dental care for inpatients. This applies not only to hospital trusts but rehabilitation and community hospitals who look after many at-risk groups for significant periods of time.

Pressures on the NHS have increased during the COVID-19 pandemic and it is important that urgent dental care services are available for 